Vishnu S.T. Srinivasamurthy, Dominique Böttcher and Uwe T. Bornscheuer*

\title{
A multi-enzyme cascade reaction for the production of 6-hydroxyhexanoic acid
}

https://doi.org/10.1515/znc-2018-0216

Received December 18, 2018; revised January 2, 2019; accepted January 3, 2019

\begin{abstract}
Multi-enzyme cascade reactions capture the essence of nature's efficiency by increasing the productivity of a process. Here we describe one such three-enzyme cascade for the synthesis of 6-hydroxyhexanoic acid. Whole cells of Escherichia coli co-expressing an alcohol dehydrogenase and a Baeyer-Villiger monooxygenase (CHMO) for internal cofactor regeneration were used without the supply of external NADPH or NADP ${ }^{+}$. The product inhibition caused by the $\varepsilon$-caprolactone formed by the CHMO was overcome by the use of lipase CAL-B for in situ conversion into 6-hydroxyhexanoic acid. A stirred tank reactor under fed-batch mode was chosen for efficient catalysis. By using this setup, a product titre of $>20 \mathrm{~g} \mathrm{~L}^{-1}$ was achieved in a $500 \mathrm{~mL}$ scale with an isolated yield of 81\% 6-hydroxyhexanoic acid.
\end{abstract}

Keywords: 6-hydroxyhexanoic acid; Baeyer-Villiger monooxygenase; Candida antartica Lipase B; cyclohexanone monooxygenase; enzyme cascade reactions; whole-cell biocatalysis.

\section{Introduction}

Nature productively performs complex enzymatic reactions in a sequential order, thus eliminating the undesired accumulation of intermediates and to attain high atom efficiency toward the desired product $[1,2]$. Scientists have adapted this strategy for the production of industrially important chemicals for environmentally benign processes. Such multi-enzyme cascade reactions provide many advantages for the process design and the overall

*Corresponding author: Uwe T. Bornscheuer, Institute of Biochemistry, Department of Biotechnology and Enzyme Catalysis, University of Greifswald, Felix-Hausdorff-Str. 4, 17487 Greifswald, Germany, Phone: +49 3834420 4367, E-mail: uwe.bornscheuer@uni-greifswald.de Vishnu S.T. Srinivasamurthy and Dominique Böttcher: Institute of Biochemistry, Department of Biotechnology and Enzyme Catalysis, University of Greifswald, Felix-Hausdorff-Str. 4, 17487 Greifswald, Germany economics. The lack of the necessity for intermediate isolation and purification reduces the solvent load and waste produced in the process [3], which in turn improves the economics of the process. Cascade reactions also make it easy to work with unstable intermediates or by shifting an unfavourable reaction equilibrium toward the end product [4-7]. Here we present a cascade reaction (Scheme 1) for the production of 6-hydroxyhexanoic acid (4), which can serve as an intermediate in polymer chemistry. Products derived from 4 includes 1,6-hexanediol via a single step hydrogenolysis [8] or adipic acid by oxidation [9]. It can also undergo direct condensation polymerization to produce co-polymers with lactic acid [10]. An interesting multi-enzyme cascade was reported by Sattler et al. where 4 was converted to 6 -aminohexanoic acid [11]. Here, 4 was first oxidized to 6-oxohexanoic acid by a primary alcohol dehydrogenase $(\mathrm{ADH})$ and then aminated to 6-aminohexanoic acid with a $\omega$-transaminase. Hence, it is interesting to establish a large-scale enzymatic production of $\mathbf{4}$.

As shown in Scheme 1, 4 is produced from the bulk substrate cyclohexanol using a three-enzyme cascade reaction. First, cyclohexanol (1) is oxidized to cyclohexanone by an $\mathrm{ADH}$ alongside the cofactor $\mathrm{NADH}^{+}$that is reduced to NADPH. Cyclohexanone (2) then undergoes a Baeyer-Villiger oxidation in the presence of cyclohexanone monooxygenase (CHMO) consuming NADPH to produce $\varepsilon$-caprolactone (3) and $\operatorname{NADP}^{+}[12,13] .3$ is then hydrolyzed to $\mathbf{4}$ by Pseudozyma antarctica Lipase B, previously named Candida antarctica Lipase B (known as CAL-B). Previously, we already reported on a system where the CHMO is combined with the ADH (or a polyol dehydrogenase) to create a self-sufficient cofactor regeneration system [14-16]. It was observed that CHMO experiences severe product inhibition by 3 above $60 \mathrm{mM}$, which could be overcome by the use of lipase CAL-A. This unique lipase has acyltransferase activity and thus enabled the formation of oligomers from $\varepsilon$-caprolactone to overcome product inhibition [16]. Later, a detailed kinetic study of the sequential cascade was reported [17]. Consequently, an extension of the ADH/CHMO cascade is crucial to establish a suitable process.

A further important aspect is the optimization of cofactor regeneration due to the high costs of NADPH/ $\mathrm{NADP}^{+}[18]$ and also the requirement of a balanced coexpression of $\mathrm{ADH}$ and CHMO [19, 20]. For this, we 


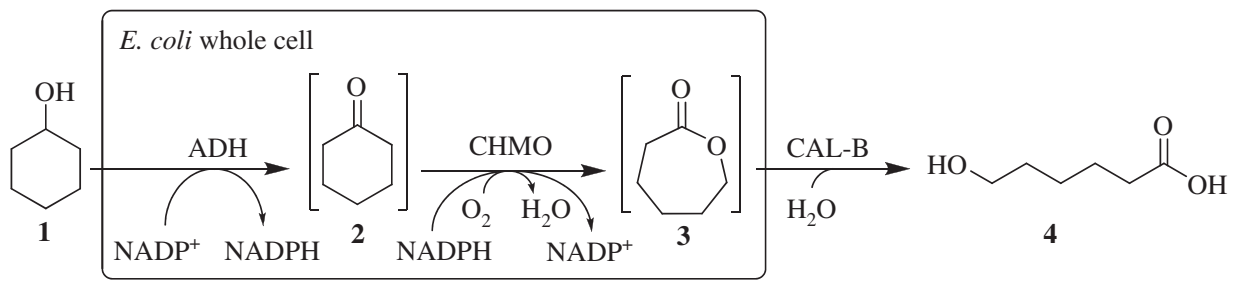

Scheme 1: Three-enzyme cascade for the production of 6-hydroxyhexanoic acid. Cyclohexanol 1 is converted to cyclohexanone 2 by an alcohol dehydrogenase (ADH) wherein NADP+ is reduced to NADPH. NADPH is then consumed in the conversion of cyclohexanone to $\varepsilon$-caprolactone 3 by the cyclohexanone monooxygenase (CHMO). Finally, Candida antarctica Lipase B (CAL-B) converts $\varepsilon$-caprolactone to 6-hydroxyhexanoic acid 4. Both $\mathrm{ADH}$ and $\mathrm{CHMO}$ were co-expressed in the same $E$. coli cell to facilitate cofactor regeneration.

developed a co-expression system where both enzymes are expressed in an optimal ratio for efficient cofactor regeneration [21]. Even though other strategies have been proposed, where the ADH and the CHMO were coexpressed as a fusion protein [20, 22], the ratio of ADH to CHMO cannot be tuned by such an approach. Also, understanding and fine-tuning the NADPH concentrations in non-growing cells could be important [23]. The co-expression of ADH and CHMO gives us an opportunity to establish the whole cascade also for the production of 4 without the need of any external cofactor addition. Additionally, this enables the whole-cell biocatalysis with a single-cell preparation where both, ADH and CHMO, are co-expressed in Escherichia coli. Here, we present the successful one-pot production of $\mathbf{4}$ using this multi-enzyme cascade starting from $200 \mathrm{mM}$ cyclohexanol.

\section{Results and discussion}

\subsection{Set-up of the cascade reaction and influence of lipase CAL-B}

CHMO is known to undergo substrate and product inhibition already starting at very low concentrations $(>8 \mathrm{mM}$ ) of cyclohexanol [17], which makes it important for the whole cascade to operate efficiently to avoid any accumulation of substrate, intermediates or $\varepsilon$-caprolactone. To avoid inhibition by high concentrations of $\mathbf{1}$, we have used a feeding strategy. To ensure rapid conversion of cyclohexanone, sufficient expression of a highly active and stable quadruple mutant of the CHMO (CHMO-QM) previously designed was crucial [20]. Finally, inhibition of the CHMO by $\mathbf{3}$ was avoided by adding lipase CAL-B to convert 3 to 4 . The aim of this small-scale biocatalysis reaction was to verify the effect of CAL-B on the overall cascade conversion. Biocatalysis was performed first in the presence or absence of CAL-B at starting concentrations of 1 ranging from 20 to $100 \mathrm{mM}$.
In the absence of CAL-B, conversion was defined by the amount of 3 produced, whereas in the presence of CAL-B it was defined by the amount of $\mathbf{4}$ produced in the cascade after $22 \mathrm{~h}$ (Figure 1). In the absence of CAL-B, 88\% conversion was achieved at $20 \mathrm{mM}$ substrate concentration, which decreased to $46 \%$ (60 mM) and only $32 \%(100 \mathrm{mM})$ at higher substrate loadings. As expected, in the presence of CAL-B, much higher conversions were observed as the inhibitory $\varepsilon$-caprolactone was converted to 4. Hence, conversion almost doubled for reactions at 60 and $100 \mathrm{mM}$ (Figure 1). Thus, also by the use of CAL-B, product inhibition can be overcome for the one-pot conversion of $\mathbf{1}$ to 4 .

\subsection{Upscaling of the cascade reaction}

As the use of CAL-B was justified by the results shown above, the cascade was upscaled to $200 \mathrm{mM}$ cyclohexanol at an operating volume of $500 \mathrm{~mL}$ in a stirred tank reactor using a fed-batch mode. The reactor was equipped with a $\mathrm{pH}$ controller as an acid is the final product and high variation of the $\mathrm{pH}$ value leads to considerable loss of enzyme activity. Biocatalysis was started by feeding cyclohexanol at a rate of its consumption by the ADH to avoid its accumulation. Molecular oxygen is required as an oxidizing reagent by the CHMO, hence, oxygen or air was bubbled into the reaction, and the concentration of the dissolved oxygen was monitored to avoid its limitation. Furthermore, because of the aeration and the volatile nature of $\mathbf{1}$, a small fraction of it could be lost in the exhaust. To collect and evaluate this loss of $\mathbf{1}$, the air out of the reactor was bubbled into an exhaust sink. Regular samples were taken from the exhaust sink for analysis.

As can be observed from Figure 2, 1 was fed at a rate of $4.1 \mu \mathrm{L} \mathrm{min}^{-1}$ for $45 \mathrm{~h}$, in accordance with the total ADH activity in the reactor. There was complete consumption of 1 during the first $12 \mathrm{~h}$, after which it started to accumulate slowly to a final concentration of $12 \mathrm{mM}$ by the end of the feeding. However, this unreacted $\mathbf{1}$ is consumed 


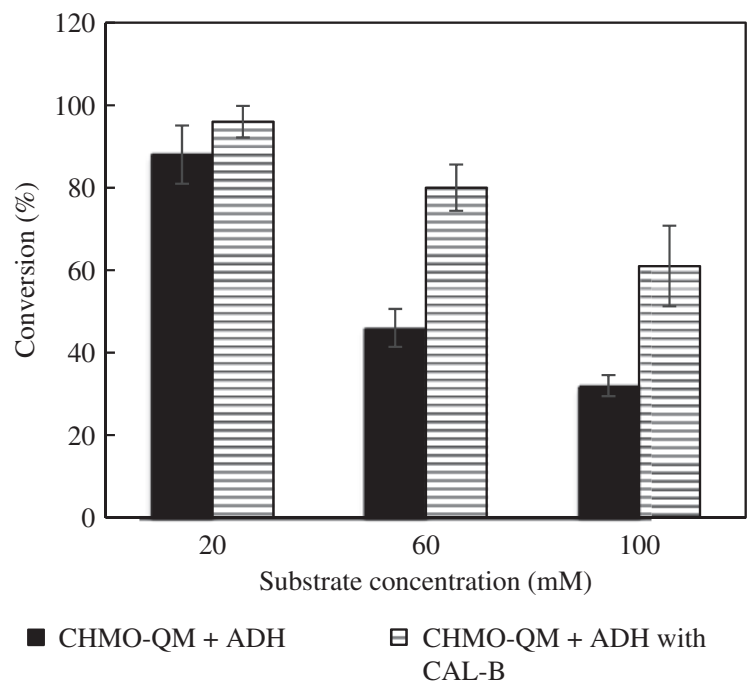

Figure 1: Comparison of the conversion of cyclohexanol with (striped bars) and without (solid bars) CAL-B. The $10 \mathrm{mg}_{\mathrm{wcw}}$ of E. coli co-expressing ADH and CHMO was added to $10 \mathrm{~mL}$ sodium phosphate buffer (20 mM, pH 7.5). For the biocatalysis with CAL-B, $20 \mathrm{mg}$ lyophilized CAL-B was added in each reaction. The reaction was started by adding 20,60 or $100 \mathrm{mM} 1$. The reaction vessel was closed with a breathable membrane to ensure oxygen supply and incubated at $30^{\circ} \mathrm{C}$ and $180 \mathrm{rpm}$. The reaction was performed in triplicates.

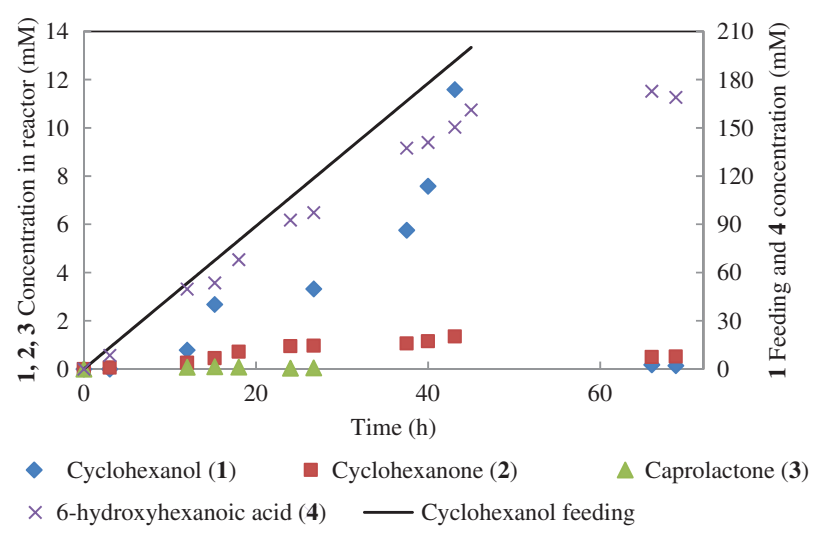

Figure 2: Variation of $\mathbf{1}$ (diamonds), $\mathbf{2}$ (squares), $\mathbf{3}$ (triangles) and 4 (cross) concentrations over time. The black line shows the feeding curve of 1 . There is no accumulation of any substrate but for the product 4 in the first $12 \mathrm{~h}$. As 1 tends to accumulate, it has an influence on the cascade efficiency and leads to the accumulation of the intermediates $\mathbf{2}$ and $\mathbf{3}$. As the concentration of $\mathbf{1}$ is kept below the inhibitory threshold value [20], it does not inhibit the CHMO-QM. The active CHMO-QM converts the accumulated 1 by the end of reaction.

completely after $70 \mathrm{~h}$. Conversely, the concentration of $\mathbf{2}$ reached a maximum residual concentration of only $1.3 \mathrm{mM}$, which further decreases to $0.3 \mathrm{mM}$ by the end of the $70 \mathrm{~h}$. Because of the presence of CAL-B, the concentration of $\mathbf{3}$ is always below the detection level. We were pleased to find that the concentration of 4 reached $168 \mathrm{mM}(11.1 \mathrm{~g}, 81 \%$ isolated yield, Supplementary Figure 1A), showing that

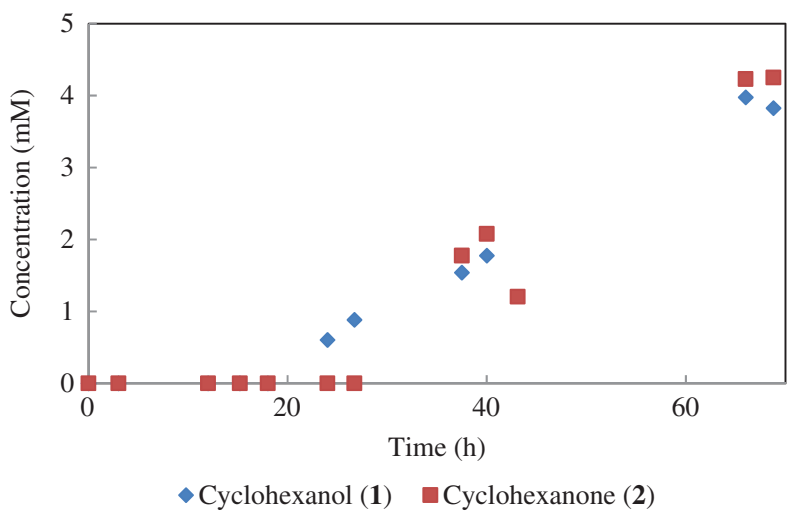

Figure 3: Variation of $\mathbf{1}$ (diamonds) and $\mathbf{2}$ (squares) with time. The exhaust gas from the reactor was bubbled into the exhaust sink. Samples were taken regularly for analysis. The accumulation of 1 and 2 in the exhaust starts only after the accumulation in the reactor.

the majority of substrate $\mathbf{1}$ was converted throughout the cascade reaction. The product identity was confirmed by ${ }^{1} \mathrm{H}-\mathrm{NMR}$ spectroscopy (Supplementary Figure 1B). A small portion of $\mathbf{1}$ and $\mathbf{2}$ ( $5 \mathrm{mM}$ each) was found in the exhaust sink because of evaporation of these volatile compounds as shown in Figure 3.

\section{Conclusions}

In summary, we successfully demonstrated the use of a three-enzyme cascade for the large-scale production of 6-hydroxyhexanoic acid. ADH and CHMO-QM were coexpressed in a single $E$. coli cell to have an efficient cofactor $\left(\mathrm{NADPH} / \mathrm{NADP}^{+}\right)$regeneration and hence to reduce the costs of the process. Additionally, whole cells of E. coli were used without the need for cell lysis, which further makes this process economically feasible. The severe product inhibition of CHMO caused by $\varepsilon$-caprolactone was solved by adding CAL-B, which in situ converts it to 6-hydroxyhexanoic acid. The effect of CAL-B was shown in small scale where the conversion almost doubles at high cyclohexanol concentration. The cascade was upscaled to produce over $20 \mathrm{~g} \mathrm{~L}^{-1}$ of product titer. Hence, the multienzyme cascade discussed may represent an economic and efficient protocol for the environmentally friendly production of 6-hydroxyhexanoic acid.

\section{Materials and methods}

Chemicals and materials: All chemicals were purchased from VWR International GmbH (Darmstadt, Germany), 
Merck KGaA (Darmstadt, Germany), Carl Roth GmbH \& Co. KG (Karlsruhe, Germany), Thermo Fisher Scientific Inc. (Waltham, MA, USA), c-Lecta GmbH (Leipzig, Germany) or abcr GmbH (Karlsruhe, Germany). All chemicals were used without further purification unless stated otherwise.

Bacterial strains and plasmids: $E$. coli BL21(DE3) [fhuA2 [lon] ompT gal ( $\lambda$ DE3) $[\mathrm{dcm}] \Delta$ hsdS $\lambda$ DE3 $=\lambda$ sBamHIo $\Delta E c o$ RI-B int::(lacI::PlacUV5::T7 gene1) i21 $\Delta$ nin5] was purchased from New England Biolabs GmbH (Frankfurt am Main, Germany). The plasmid pRSFDuet ${ }^{\mathrm{TM}}-1$ was purchased from Merck KGaA (Darmstadt, Germany).

Enzyme expression and production of $E$. coli whole cells: The ADH and CHMO were heterologously coexpressed in $E$. coli BL21(DE3) through a pRSFDuet ${ }^{\mathrm{TM}}$ vector as described previously [21]. Lactobacillus kefir ADH was cloned in the second ribosome binding site (RBS) of the duet vector, whereas Acinetobacter calcoaceticus CHMO with four mutations (C376L/M400I/T415C/A463C) to enhance the stability [20] was cloned at the first RBS on the pRSFDuet ${ }^{\mathrm{TM}}$ vector. An overnight culture was inoculated and grown at $37{ }^{\circ} \mathrm{C}$ in LB media $\left(5 \mathrm{~g} \mathrm{~L}^{-1}\right.$ yeast extract, $10 \mathrm{~g} \mathrm{~L}^{-1}$ tryptone, $10 \mathrm{~g} \mathrm{~L}^{-1}$ sodium chloride) supplemented with $50 \mathrm{mg} \mathrm{L}^{-1}$ kanamycin. The main culture was performed in an unbaffled shake flask. TB media ( $12 \mathrm{~g} \mathrm{~L}^{-1}$ tryptone, $24 \mathrm{~g} \mathrm{~L}^{-1}$ yeast extract, $16.4 \mathrm{~g} \mathrm{~L}^{-1} \mathrm{~K}_{2} \mathrm{HPO}_{4} \times 3 \mathrm{H}_{2} \mathrm{O}, 2.2 \mathrm{~g} \mathrm{~L}^{-1}$ $\mathrm{KH}_{2} \mathrm{PO}_{4}, 4 \mathrm{~mL} \mathrm{~L}^{-1}$ glycerol) with $50 \mathrm{mg} \mathrm{L}^{-1}$ were inoculated with the overnight culture and incubated at $37^{\circ} \mathrm{C}, 180 \mathrm{rpm}$, in a New Brunswick ${ }^{\mathrm{TM}}$ shaker, until the $\mathrm{OD}_{600}$ reached 1.0-1.2. Then enzyme expression was induced by adding $0.2 \mathrm{mM}$ IPTG and expression at $20^{\circ} \mathrm{C}$ for $12-16 \mathrm{~h}$. Later, the cells were harvested and washed once with sodium phosphate buffer (50 mM, pH 7.0) and centrifuged at 10,000 g, $4^{\circ} \mathrm{C}$ for $20 \mathrm{~min}$. The cell pellet was resuspended in sodium phosphate buffer (20 mM, pH 7.5) with 1\% DMSO and incubated for $30 \mathrm{~min}$ at $4{ }^{\circ} \mathrm{C}$. Lastly, the cells were washed once in the reaction buffer and used for whole-cell biocatalysis.
Small-scale biotransformation: E. coli whole cells (harbouring $\mathrm{ADH}$ and $\mathrm{CHMO}$ ) were resuspended in icecold sodium phosphate buffer (20 mM, pH 7.5) to a final concentration of $100 \mathrm{~g} \mathrm{~L}^{-1}$. All reactions were performed in $100 \mathrm{~mL}$ Erlenmeyer flasks and in triplicates. A total of $9 \mathrm{~mL}$ of sodium phosphate buffer (20 mM, pH 7.5) and $1 \mathrm{~mL}$ $E$. coli whole cell stock was pipetted into each reaction flask. The reaction was started by adding 20,60 or $100 \mathrm{mM}$ of $\mathbf{1}$ into the reaction flask, and this was closed with a breathable membrane for efficient $\mathrm{O}_{2}$ transfer. The flasks were incubated for $22 \mathrm{~h}$ at $30{ }^{\circ} \mathrm{C}$ and $180 \mathrm{rpm}$. Samples were taken before and after the incubation and stored at $-20^{\circ} \mathrm{C}$ until analysis.

Large-scale biotransformation: Large-scale biocatalysis was performed in New Brunswick ${ }^{\mathrm{TM}}$ BioFlo $^{\circledR} 110$ bioreactors (Eppendorf AG, Hamburg, Germany), equipped with the BioCommand ${ }^{\circledR}$ software. A total of $450 \mathrm{~mL}$ Tris$\mathrm{HCl}$ buffer (200 mM, pH 8.0) was transferred into the reactor. The $\mathrm{pH}$ sensor and the dissolved oxygen sensor were calibrated and introduced into the reactor. The temperature was set to $30{ }^{\circ} \mathrm{C}$ and maintained by a temperature regulator. Heating or cooling was performed by an electric heating jacket or cooling loop, respectively. The $14.4 \mathrm{~g}_{\mathrm{wcw}} E$. coli whole cells co-expressing ADH and CHMO were prepared as described above and dissolved in $45 \mathrm{~mL}$ of Tris-HCl buffer (200 mM, pH 8.0). The cell suspension was then introduced into the reactor. A stock solution was prepared by dissolving $1 \mathrm{~g}$ lyophilized CAL-B in $5 \mathrm{~mL}$ reaction buffer and introduced into the reactor. Pure oxygen was bubbled into the reaction at 2 vvm through a sterile filter. $\mathrm{pH}$ and dissolved oxygen were recorded by the respective probes. A PID controller was used to stabilize the $\mathrm{pH}$ with either acid (15\% v/v phosphoric acid) or base (15\% w/v sodium hydroxide). Constant mixing was achieved by an overhead stirrer at $500 \mathrm{rpm}$. The exhaust gas from the reactor was bubbled into a $4 \mathrm{~L}$ water reservoir

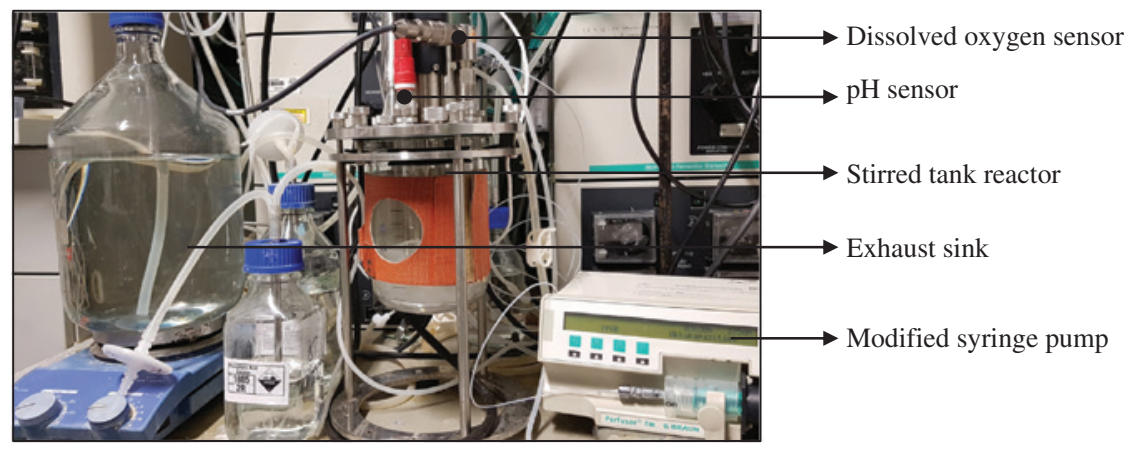

Figure 4: Setup of a stirred tank reactor. The fermenter was used as a stirred tank reactor and hence was equipped with temperature, $\mathrm{pH}$, dissolved oxygen controller and regulator. An exhaust sink was used to trap the volatile 1 or $\mathbf{2}$ escaped from the reactor. A modified syringe pump was used for uniform feeding of 1 . 
with continuous stirring to trap the volatile compounds. The complete setup is shown in Figure 4. The reaction was started by feeding 1 at a constant rate of $4.1 \mu \mathrm{L} \mathrm{min}^{-1}$ using a modified syringe pump. Samples were taken at regular intervals from the reactor and the exhaust sink and stored at $-20^{\circ} \mathrm{C}$ until further analysis.

Product isolation and characterization: The reaction media was acidified to $\mathrm{pH} 1.5$ by the addition of conc. $\mathrm{HCl}$ and vortexed for $5 \mathrm{~min}$. Then the cell debris was separated by centrifugation at $10,000 \mathrm{~g}, 25^{\circ} \mathrm{C}$ for $20 \mathrm{~min}$. The supernatant was then extracted three times with dichloromethane, and all the dichloromethane fractions were pooled. The product was isolated by distilling the solvent at $40{ }^{\circ} \mathrm{C}$ and atmospheric pressure. The product purity was analyzed using high-performance liquid chromatography (HPLC), as stated below and verified by ${ }^{1} \mathrm{H}$-NMR. NMR spectra were recorded on a Bruker Avance II 300 with a 5 mm PABBO BB-1H/D Z-GRD Z104 275/0398 probe head. Tetramethylsilane was used for calibration of the ${ }^{1} \mathrm{H}$ measurements. The purified 6-hydroxyhexanoic acid was dissolved in $\mathrm{CD}_{3} \mathrm{OD}$ and was measured at $300 \mathrm{~Hz}$. To assign proton atoms, 1D NMR technique was used.

Quantitative analysis using gas chromatography (GC) and HPLC: The samples were analyzed using GC to quantify $\mathbf{1}, \mathbf{2}$ and $\mathbf{3}$ whereas HPLC was used to quantify $\mathbf{4}$. For GC quantification, $200 \mu \mathrm{L}$ of each sample was extracted with $600 \mu \mathrm{L}$ dichloromethane (containing $2 \mathrm{mM}$ acetophenone as external standard) by vortexing for $1 \mathrm{~min}$. The two phases were separated by centrifugation at 13,000 $\mathrm{g}$ for $5 \mathrm{~min}$. The organic phase was carefully transferred to a sterile microcentrifuge tube and dried with anhydrous sodium sulfate. The final sample was analyzed using a Shimadzu GC 14A or Shimadzu 2010 Plus equipped with Hydrodex $^{\circledR}-\beta 3$ P column $(0.25 \mathrm{~mm} \times 25 \mathrm{~m}$, Macherey \& Nagel, Düren, Germany) and flame-ionization detection. The oven was preheated to $60^{\circ} \mathrm{C}$ for $10 \mathrm{~min}$, followed by a gradual increase of temperature by $10^{\circ} \mathrm{C} \mathrm{min}^{-1}$ to reach 160 ${ }^{\circ} \mathrm{C}$ and held at this oven temperature for $10 \mathrm{~min}$. Retention times of $\mathbf{1}, \mathbf{2}$ and $\mathbf{3}$ were 15.2, 12.9 and $20 \mathrm{~min}$, respectively.

For the quantification of $\mathbf{4}$, the sample was first acidified by adding $10 \mu \mathrm{L} 5 \mathrm{~N} \mathrm{HCl}$ to a $200 \mu \mathrm{L}$ sample, and this was vortexed. Cell debris was then removed by centrifugation at 13,000 $\mathrm{g}$ for $5 \mathrm{~min}$. A $50 \mu \mathrm{L}$ sample was injected to a Luna ${ }^{\circledR} \mathrm{C}-8$ column $(250 \mathrm{~mm} \times 4 \mathrm{~mm}$, Phenomenex, Aschaffenburg, Germany). A mixture of double distilled water ( $\mathrm{pH} 2.5)$ and acetonitrile (85/15 v/v) was used as a mobile phase at a flow rate of $1 \mathrm{~mL} \mathrm{~min}^{-1}$, and the column temperature was maintained at $40^{\circ} \mathrm{C}$. The product was detected by measuring the absorbance at $200 \mathrm{~nm}$ with a retention time of $5.1 \mathrm{~min}$.

\section{References}

1. Muschiol J, Peters C, Oberleitner N, Mihovilovic MD, Bornscheuer UT, Rudroff F. Cascade catalysis-strategies and challenges en route to preparative synthetic biology. Chem Commun 2015;51:5798-811.

2. Rudroff F, Mihovilovic MD, Gröger H, Snajdrova R, Iding H, Bornscheuer UT. Opportunities and challenges for combining chemoand biocatalysis. Nat Catal 2018;1:12-22.

3. Rudroff F. Whole-cell based synthetic enzyme cascades - light and shadow of a promising technology. Curr Opin Chem Biol 2019;49:84-90.

4. Mayer SF, Kroutil W, Faber K. Enzyme-initiated domino (cascade) reactions. Chem Soc Rev 2001;30:332-9.

5. Ricca E, Brucher B, Schrittwieser JH. Multi-enzymatic cascade reactions: overview and perspectives. Adv Synth Catal 2011;353:2239-62.

6. Wheeldon I, Minteer SD, Banta S, Barton SC, Atanassov P, Sigman M. Substrate channelling as an approach to cascade reactions. Nat Chem 2016;8:299-309.

7. Sperl JM, Sieber V. Multienzyme cascade reactions - status and recent advances. ACS Catal 2018;8:2385-496.

8. Dougherty EF, inventor; Celanese Corp, assignee. Production of alcohols from carboxylic acids. United States patent US 3,985,814. 1976.

9. Changjiu X, Yongjia Y, Yi Z, Min L, Bin Z, Xinxin P, et al. Onepot synthesis of 6-hydroxyhexanoic acid from cyclohexanone catalyzed by dealuminated HBEA zeolite with aqueous $30 \% \mathrm{H}_{2} \mathrm{O}_{2}$ solution. China Pet Process Pe 2018;20:1-6.

10. Ajioka M, Suizu H, Higuchi C, Kashima T. Aliphatic polyesters and their copolymers synthesized through direct condensation polymerization. Polym Degrad Stab 1998;59:137-43.

11. Sattler JH, Fuchs M, Mutti FG, Grischek B, Engel P, Pfeffer J, et al. Introducing an in situ capping strategy in systems biocatalysis to access 6-aminohexanoic acid. Angew Chem Int Ed Engl 2014;53:14153-7.

12. Sheng D, Ballou DP, Massey V. Mechanistic studies of cyclohexanone monooxygenase: chemical properties of intermediates involved in catalysis. Biochemistry 2001;40:11156-67.

13. Tolmie C, Smit MS, Opperman DJ. Native roles of Baeyer-Villiger monooxygenases in the microbial metabolism of natural compounds. Nat Prod Rep 2019. https://doi.org/10.1039/c8np00054a.

14. Mallin $\mathrm{H}$, Wulf $\mathrm{H}$, Bornscheuer UT. A self-sufficient Baeyer-Villiger biocatalysis system for the synthesis of $\varepsilon$-caprolactone from cyclohexanol. Enzyme Microb Technol 2013;53:283-7.

15. Staudt S, Bornscheuer UT, Menyes U, Hummel W, Gröger H. Direct biocatalytic one-pot-transformation of cyclohexanol with molecular oxygen into $\varepsilon$-caprolactone. Enzyme Microb Technol 2013;53:288-92.

16. Schmidt S, Scherkus C, Muschiol J, Menyes U, Winkler T, Hummel W, et al. An enzyme cascade synthesis of $\varepsilon$-caprolactone and its oligomers. Angew Chem Int Ed Engl 2015;54:2784-7.

17. Scherkus C, Schmidt S, Bornscheuer UT, Gröger H, Kara S, Liese A. Kinetic insights into $\varepsilon$-caprolactone synthesis: improvement of an enzymatic cascade reaction. Biotechnol Bioeng 2017;114:1215-21.

18. Hollmann F, Kara S, Opperman DJ, Wang Y. Biocatalytic synthesis of lactones and lactams. Chem Asian J 2018;13:3601-10. 
19. Scherkus C, Schmidt S, Bornscheuer UT, Gröger H, Kara S, Liese A. A fed-batch synthetic strategy for a three-step enzymatic synthesis of poly- $\varepsilon$-caprolactone. ChemCatChem 2016;8:3446-52.

20. Schmidt S, Büchsenschütz HC, Scherkus C, Liese A, Gröger $\mathrm{H}$, Bornscheuer UT. Biocatalytic access to chiral polyesters by an artificial enzyme cascade synthesis. ChemCatChem 2015;7:3951-5.

21. Kohl A, Srinivasamurthy V, Böttcher D, Kabisch J, Bornscheuer UT. Co-expression of an alcohol dehydrogenase and a cyclohexanone monooxygenase for cascade reactions facilitates the regeneration of the NADPH cofactor. Enzyme Microb Technol 2018;108:53-8.
22. Aalbers FS, Fraaije MW. Coupled reactions by coupled enzymes: alcohol to lactone cascade with alcohol dehydrogenasecyclohexanone monooxygenase fusions. Appl Microbiol Biotechnol 2017;101:7557-65.

23. Walton AZ, Stewart JD. Understanding and improving NADPHdependent reactions by nongrowing Escherichia coli cells. Biotechnol Prog 2004;20:403-11.

Supplementary Material: The online version of this article offers supplementary material (https://doi.org/10.1515/znc-2018-0216). 